\title{
Determination of copper in whole blood by differential pulse adsorptive stripping voltammetry
}

\author{
Tarik Attar, Yahia Harek and Lahcène Larabi * \\ Laboratoire d'Electrochimie et Chimie Analytique, Département de Chimie, Faculté des Sciences, \\ Université Abou Bekr Belkaid, Tlemcen 13000, Algeria
}

\begin{abstract}
A selective and sensitive method for determination of copper in blood by adsorptive differential pulse cathodic stripping voltammetry is presented. The method is based on adsorptive accumulation of the complexes of $\mathrm{Cu}$ (II) ions with benzenesulfonyl hydrazide onto hanging mercury drop electrode (HMDE), followed by the reduction of the adsorbed species by differential pulse cathodic stripping voltammetry. The effect of various parameters such as supporting electrolyte, concentration of benzenesulfonyl hydrazide, accumulation potential, accumulation time and stirring rate on the selectivity and sensitivity were studied. The optimum conditions for determination of copper include perchloric acid $0.03 \mathrm{M}$, concentration of benzenesulfonyl hydrazide $7.5 \times 10^{-5} \mathrm{M}$, the accumulation potential of $-350 \mathrm{mV}$ (vs. $\mathrm{Ag} / \mathrm{AgCl}$ ), the accumulation time of $50 \mathrm{~s}$, and the scan rate of $50 \mathrm{mV} \mathrm{s}^{-1}$. Under optimized conditions, linear calibration curves were established for the concentration of $\mathrm{Cu}$ (II) in the range of $0.62-275 \mathrm{ng} \mathrm{mL}^{-1}$, with detection limit of $0.186 \mathrm{ng} \mathrm{mL}^{-1}$ for $\mathrm{Cu}$ (II). The procedure was successfully applied to the determination of copper ion in whole blood samples.
\end{abstract}

Keywords: Copper, Benzenesulfonyl hydrazide, Adsorptive stripping Voltammetry, Whole blood.

\section{Introduction}

Copper is one of several essential trace metals that are important in supporting biological functions for the human organism, forming part of many copper dependent enzymes and proteins joined to copper ${ }^{1,2}$. Early reports of an essential role for copper in supporting normal levels of hemoglobin in blood and to prevent anemia came out in the middle of the 19 th century ${ }^{3,5}$. Since then, evidence has accumulated that supports a requirement for dietary copper in humans for optimal function of all biological systems ${ }^{6,7}$. Copper is an element with biological significance to the cardiovascular disease patient ${ }^{8,10}$.

Electroanalytical techniques have important advantages that include speed, high selectivity and sensitivity, low detection limit, relative simplicity, and low equipment cost compared to other techniques ${ }^{11,15}$. Of these electroanalytical methods, stripping voltammetry is the most sensitivity one because it has a preconcentration step on the electrode surface prior to recording the voltammogram ${ }^{16,18}$. Responding to the need to apply this sensitive method to those substances that cannot be preconcentrated by electrolysis at the electrode surface, an alternative principles have been proposed for the accumulation of the analyte via the *Corresponding author:

E-mail address: larabi_lahcene@yahoo.fr DOI: http://dx.doi.org/10.13171/mjc.2.6.2014.21.02.25 
utilization of the adsorption phenomena. In the adsorptive stripping voltammetry (AdSV) accumulation of the analyte occurs by physical adsorption rather than by electrolytic deposition.

However, depending on the oxidation-reduction properties of the accumulated analyte, it is determined by scanning the potential in appropriate negative or positive direction. Many organic molecules have a strong tendency to be adsorbed from aqueous solution onto a mercury surface. Additionally, many inorganic cations have been determined by AdSV technique after their complexation with surface-active complex agents.

The technique is based upon adsorptive accumulation of the metal ion complexed with a suitable ligand at the electrode (HMDE) and then scanning the potential of the electrode in the negative direction ${ }^{19}$. The advantage of a hanging mercury drop electrode (HMDE) is its reliability. With the formation of each new drop, a new electrode surface is produced, which is important for unattended trace metal monitoring activities ${ }^{20,21}$. The drops generated by modern $\mathrm{Hg}$ drop electrodes are very small, and safe storage and recycling of the used $\mathrm{Hg}$ will ensure minimal environmental risks ${ }^{22}$.

These techniques are advantageous due to their possibility to be utilized in analysis of trace elements, their complexes, various inorganic and organic compounds in aqueous as well as non aqueous solution systems ${ }^{23,26}$. Numerous electrochemical stripping procedures including anodic stripping voltammetry (ASV) and adsorptive cathodic stripping voltammetry (AdCSV) have been described for the determination of copper ${ }^{27,32}$.

The present study attempts to describe a new adsorptive cathodic stripping procedure for determination of trace amounts of copper by using benzenesulfonyl hydrazide (BSH) (Scheme 1) as a complexing agent. The method is based on the effective accumulation of the $\mathrm{Cu}$ (II) complex with BSH onto the hanging mercury drop electrode (HMDE) followed by the stripping voltammetric measurements at the reduction current of the adsorbed complex at $0.35 \mathrm{~V}$ vs. $\mathrm{Ag} / \mathrm{AgCl}$. This method has low detection limit and is able to determine copper in different real samples.<smiles>NNS(=O)(=O)c1ccccc1</smiles>

Scheme 1: Benzenesulfonyl hydrazide (BSH)

\section{Experimental Section}

\section{Equipment and Materials}

Adsorptive cathodic stripping voltammetry (AdCSV) was carried out on Radiometer Polarograph MDE 150 recorded to the analyser POL 150. The three-electrode classical cell consisted of an HMDE, an auxiliary platinum electrode, and an $\mathrm{Ag} / \mathrm{AgCl} / \mathrm{KCl}(3 \mathrm{M} \mathrm{KCl})$ reference electrode, a mechanical mini stirrer, and a capillary to supply an inert gas. A magnetic stirrer and stirring bar provided the convective transport during accumulation.

The whole procedure was automated and controlled through the programming capacity of the apparatus with Trace- Master 5 PC software. The solutions were de-aerated using highpurity argon. 


\section{Procedure}

Ten milliliters of the supporting electrolyte solution were pipetted into the cell and deoxygenated with argon for $5 \mathrm{~min}$. The accumulation potential (usually $-350 \mathrm{mV}$ ) was applied to a fresh mercury drop while the solution was stirred. The stirring was then stopped, and after $20 \mathrm{~s}$ under rest the voltammogram was recorded by applying a negative-going potential scan. After background stripping voltammograms were obtained, the entire cycle was repeated in the presence of the analyte, using a new mercury drop. The influence of the surface area of the working mercury electrode on the peak was also studied.

As expected, an increase of the electrode surface area generated a higher peak current so a mercury drop of a large area (Dropping times of $1 \mathrm{~s}$ ) was considered in the present study. The influence of the rest time was also considered and a time period of $20 \mathrm{~s}$ was chosen.

Following the accumulation period, the stirring was stopped and after $5 \mathrm{~s}$ the voltammogram was recorded by applying a negative-biased scan. All data were obtained at room temperature.

\section{Reagents}

All chemicals used were of analytical-reagent grade or the highest purity available. Aqueous solutions were prepared by dissolving a certain amount of chemicals into high-purity deionized water (MilliQ water system). Acids used for the analysis, the nitric acid (69.5\%, Fluka) and the perchloric acid (70-72\%, Merck). Stock solution of copper (1000 ppm, atomic adsorption standard, Aldrich) was prepared in deionized water and a $5 \times 10^{-3} \mathrm{M}$ benzenesulfonyl hydrazide (Aldrich 98\%).

\section{Blood sample preparation}

Approximately $1 \mathrm{~mL}$ blood samples were taken from 31 healthy human with special care, by vein puncture using disposable syringes and needles. The samples $(1 \mathrm{~mL})$ were then digested with nitric acid and perchloric acid (3:1). Digested samples were made up to $5 \mathrm{~mL}$ using $0.25 \%$ nitric acid. Special care was taken to avoid all contaminations. Only reagents with low background impurities were used.

\section{Results and Discussion}

Preliminary experiments were performed to identify the general features which characterise the behaviour of $\mathrm{Cu}$ and benzenesulfonyl hydrazide systems on mercury drop electrode. Figure 1 shows cathodic stripping differential pulse voltammograms of the $\mathrm{Cu}$ BSH systems in $0.03 \mathrm{M}$ perchloric acid $\left(\mathrm{HClO}_{4}\right)$, after accumulation at $-350 \mathrm{mv}$ for $50 \mathrm{~s}$ on a HMDE.The blank solution (the ligand without metal ions) in $0.03 \mathrm{M} \mathrm{HClO}_{4}$ (curve a) does not show any peak in the studied potential range. Curve b shows the voltammogram of a solution containing $75 \mathrm{ng} \mathrm{mL}^{-1}$ of copper in the absence of ligand under similar conditions.

The two curves are identical. The voltammogram (curve c) of the sample solution containing the metal ions with the ligand shows peak at $-475 \mathrm{mV}$. This obtained polarographic wave is probably due to the electrochemical reduction of $\mathrm{Cu}$ (II) complexe with benzenesulfonyl hydrazide in $0.03 \mathrm{M} \mathrm{HClO}_{4}$. A proposed mechanism for the electrochemical reduction of this electroactive group is as follows:

-The metal ion $\mathrm{Cu}^{2+}$ reacts with a ligand $\mathrm{BSH}$ to form the complex in solution. The complex is then adsorbed onto the electrode surface. 


$$
\begin{aligned}
& \mathrm{Cu}^{2+}+\mathrm{nBSH}_{(\mathrm{sol})} \leftrightarrows \mathrm{Cu}(\mathrm{BSH})_{\mathrm{n}}{ }^{2+}(\text { sol }) \\
& \mathrm{Cu}(\mathrm{BSH})_{\mathrm{n}}{ }^{2+}(\text { sol }) \quad \leftrightarrows \mathrm{Cu}(\mathrm{BSH})_{\mathrm{n}}{ }^{2+}(\text { ads })
\end{aligned}
$$

-These steps are followed by the reduction of ion complex during the negative scan direction.

$$
\mathrm{Cu}(\mathrm{BSH})_{\mathrm{n}^{2+}}{ }^{(\mathrm{ads})}+2 \mathrm{e}^{-} \leftrightarrows \mathrm{Cu}(\mathrm{Hg})+\mathrm{nBSH}_{(\mathrm{ads})}
$$

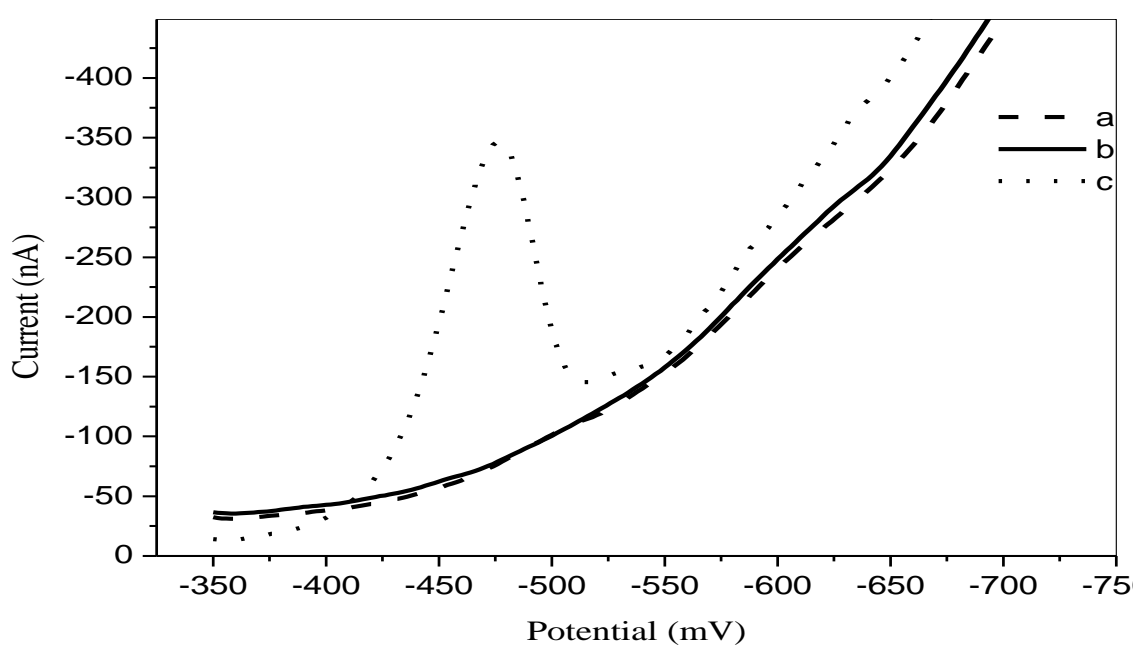

Figure 1. Adsorptive stripping voltammograms of a) Blank solution (ligand without metal copper); b) Copper (75 $\left.\mathrm{ng} \mathrm{mL}^{-1}\right)$ ions without the ligand; c) Copper $\left(75 \mathrm{ng} \mathrm{mL}^{-1}\right)$ complex with ligand (BSH); Conditions: $0.03 \mathrm{M} \mathrm{HClO}_{4}$, BSH : $7.5 \times 10^{-5} \mathrm{M}$; accumulation time, $50 \mathrm{sec}$; accumulation potential, $-350 \mathrm{mV}$; scan rate, $50 \mathrm{mV} \mathrm{s}^{-1}$ (modulation time, $20 \mathrm{~ms}$; modulation amplitude, $-50 \mathrm{mV}$ )

\section{Effects of the variables}

For the best sensitivity in determination of copper, the influence of different parameters such as supporting electrolytes, ligand concentration, deposition time and potential, stirring and scan rate were investigated. The experimental variables were optimised as below.

\section{Effect of supporting electrolyte}

The sensitivity of the differential pulse-adsorptive stripping procedure for a particular analyte is usually significantly influenced by the composition of the supporting electrolyte.

Consequently, several supporting electrolytes such as potassium nitrate, sodium hydroxide, citrate and sodium acetate-acetic acid buffer, perchloric acid, nitric acid and hydrochloric acid were evaluated after $50 \mathrm{~s}$ accumulation time at $-0.35 \mathrm{~V}$ accumulation potential. Among these supporting electrolytes the best electroanalytical signal in terms of DP-AdCSV peak current intensity and shape was obtained with perchloric acid, which was selected as optimal for further works. Thus, the influence of the concentration of supporting electrolyte on the cathodic stripping peak currents of copper was studied in the concentrations range of 0.01 to $0.1 \mathrm{M}$. The results show that with increasing the concentrations of supporting electrolyte to about $0.03 \mathrm{M}$ the peak currents for copper increase. This phenomenon is due to the enhanced complexing ability of BSH in large concentration values.

However, when concentrations greater than $0.03 \mathrm{M}$ were employed, the peak current decreased considerably. The influence of concentration on the observed voltammetric signal 
is illustrated in Fig. 2, which indicates that a concentration of $0.03 \mathrm{M}$ would be an adequate optimum for succeeding investigations.

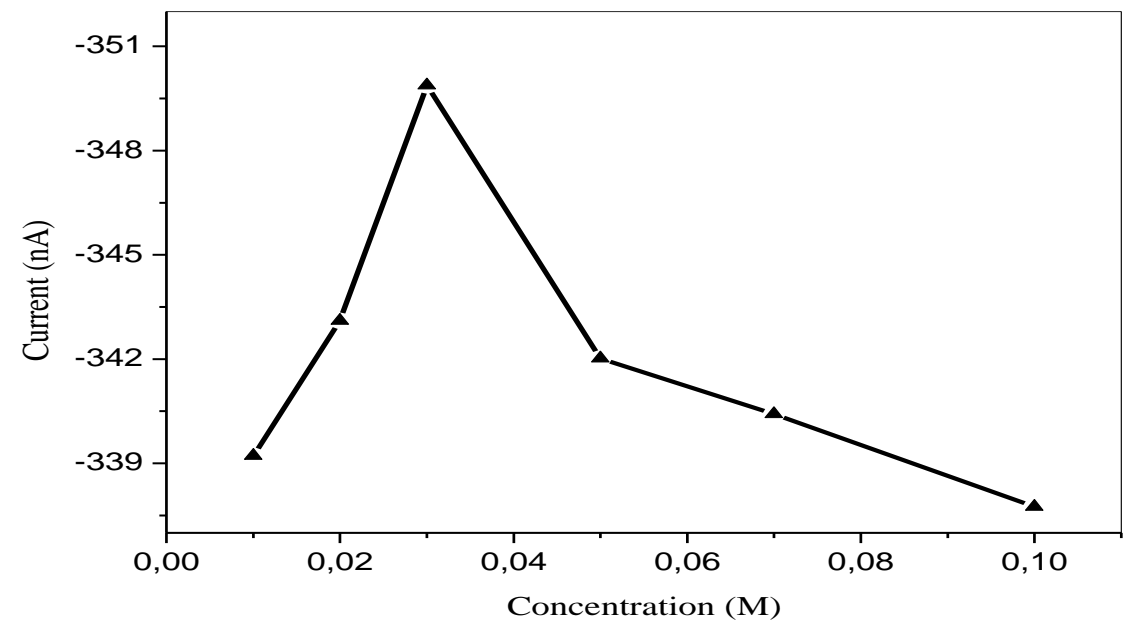

Figure 2. Effect of concentration of supporting electrolyte on the peak current, conditions: Copper (75 $\left.\mathrm{ng} \mathrm{mL}^{-1}\right)$; $\mathrm{BSH}: 7.5 \times 10^{-5} \mathrm{M}$; accumulation time, $50 \mathrm{sec}$; accumulation potential, $350 \mathrm{mV}$; scan rate, $50 \mathrm{mV} \mathrm{s}^{-1}$ (modulation time, $20 \mathrm{~ms}$; modulation amplitude, $-50 \mathrm{mV}$ ).

\section{Effect of accumulation potential}

The adsorption takes place at fixed potential which depends on the charge of the adsorbed species and the value of zero potential charge of the mercury electrode in the electrolyte in question. For the neutral species, the application of a potential close to the zero potential charge is more favourable for the accumulation. Thus, accumulation potential is an important parameter for stripping techniques that influences the sensitivity of the determination. The effect of accumulation potential on the stripping peak current of the complex was examined over the potential range of -250 to $-450 \mathrm{mV}$. As shown in Figure 3 the peak current increased with changing potential from -250 to $-350 \mathrm{~V}$.

However, the cathodic stripping peak current decreased when potentials greater than from $350 \mathrm{mV}$ were used. This current decrease is due to complex reduction during adsorption step. Thus, an accumulation potential of $-350 \mathrm{mV}$ was used for the optimized analytical procedure.

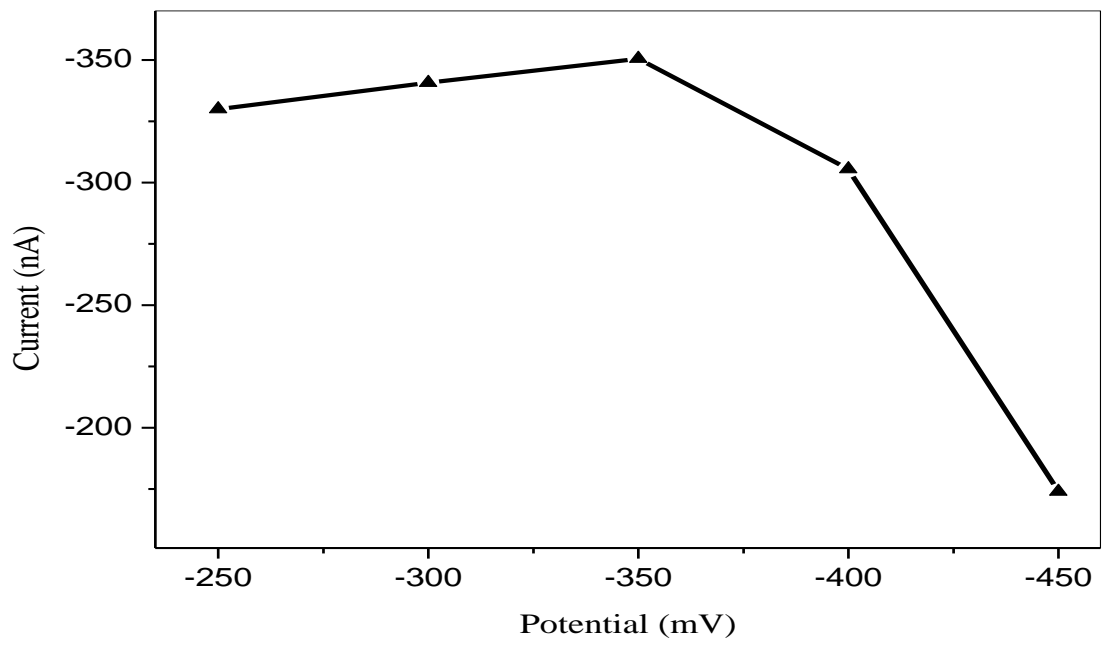

Figure 3. Effect of deposition potential on the peak current, conditions same as in Fig. 2 


\section{Effect of variation of accumulation time}

The effect of accumulation time on the efficiency of the collection of copper complex with BSH $\left(7.5 \times 10^{-5} \mathrm{M}\right)$ onto the working electrode surface was evaluated by raising the accumulation time over the range of $0-70 \mathrm{~s}$.

The resulting peak current-accumulation time (ip - $t_{\text {acc }}$ ) profile is exhibited in Fig. 4 and as can be seen from this plot, a steady enhancement in the peak current was observed over the range $0-50 \mathrm{~s}$ and thereafter the peak intensity nearly decreased probably due to the saturation of the HMDE surface. Hence, $50 \mathrm{~s}$ accumulation time was selected for all the future experiments.

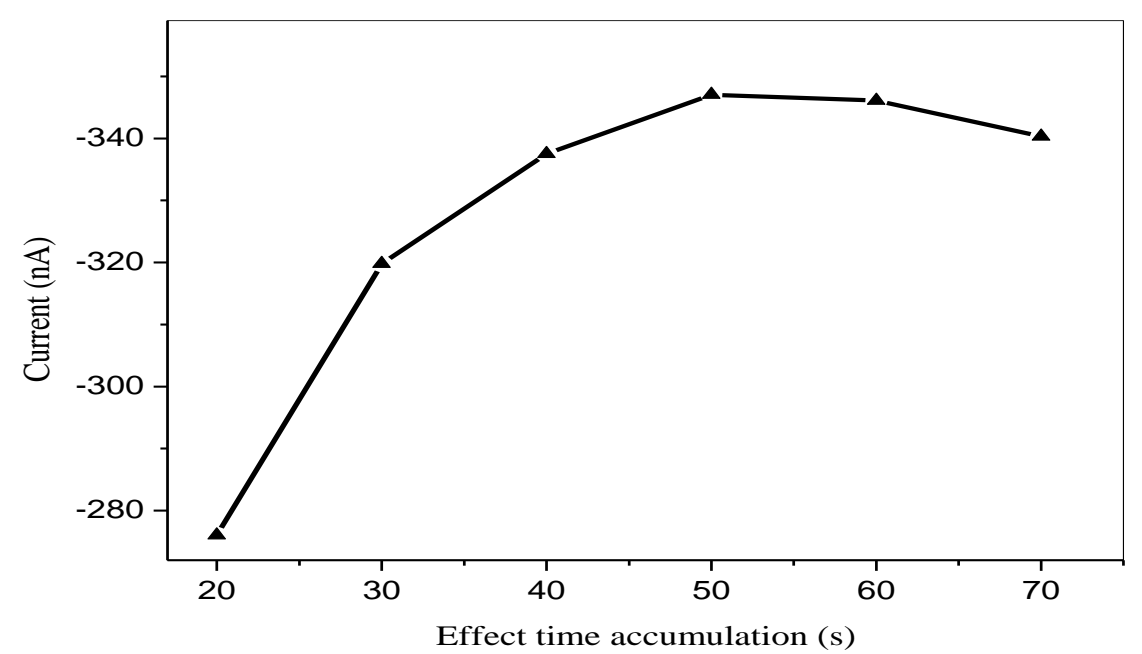

Figure 4. Influence of accumulation time on the peak current, conditions same as in Fig. 2

\section{Effect of stirring rate}

Agitation of the sample solution facilitated the mass transfer process. In present work, the samples were agitated at various stirring rates $(150,225,300,400,525$ and $650 \mathrm{rpm})$. The result showed that the current intensity efficiency was first improved with increased agitation rate before $400 \mathrm{rpm}$ and then remained nearly constant after that value (Fig. 5). Hence, a stirring rate of $400 \mathrm{rpm}$ was chosen for further studies.

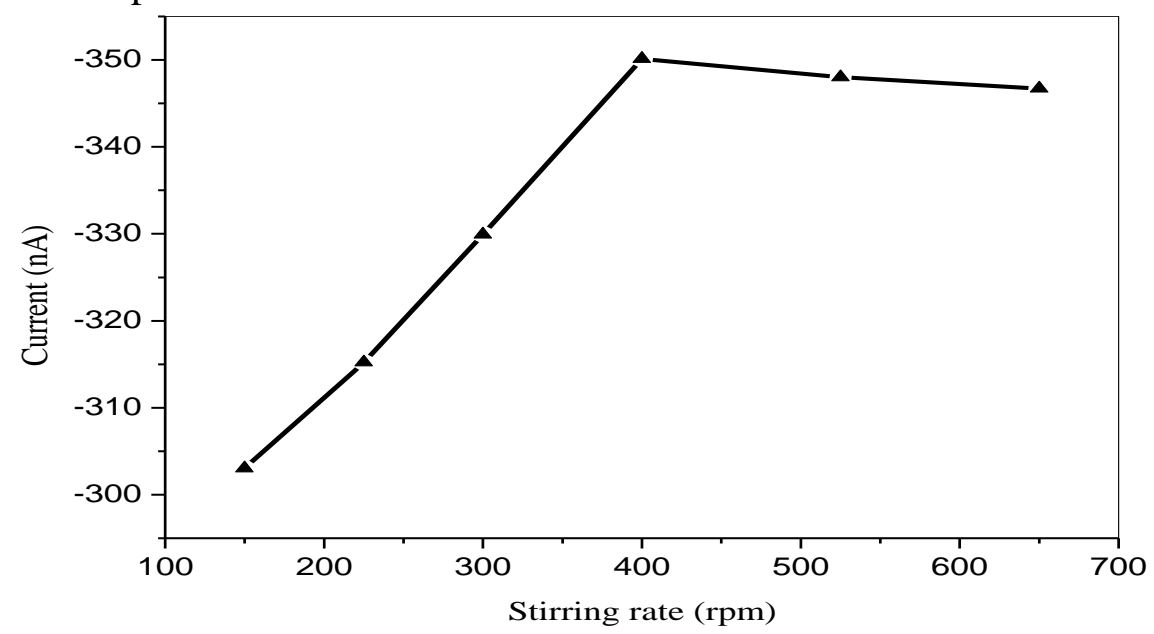

Figure 5. Influence of stirring rate on the peak current, conditions same as in Fig. 2 


\section{Effect of the scan rate}

The observed stripping voltammetric signal (peak current) can be further maximized by adjusting the way the applied potential was scanned. The effect of scan rate on the peak current of benzenesulfonyl hydrazide was studied over the range of $5-100 \mathrm{mV} \mathrm{s}^{-1}$. When the scan rate was increased from 5 to $50 \mathrm{mV} \mathrm{s}^{-1}$, the peak current increased (Fig. 6). However, at scan rates higher than $50 \mathrm{mV} \mathrm{s}^{-1}$ the peak current decreases slightly. In this work, a potential scan rate of $50 \mathrm{mV} \mathrm{s}^{-1}$ was chosen and used in all the experiments.

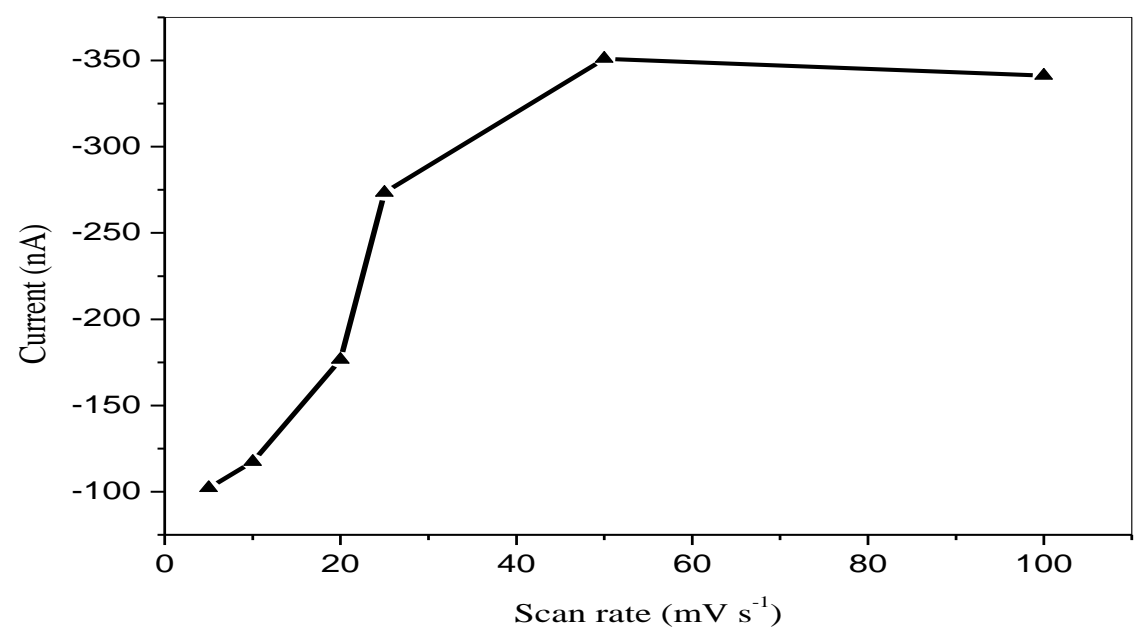

Figure 6. Influence of scan rate on the peak current, conditions same as in Fig. 2

\section{Influence of Benzenesulfonyl hydrazide concentration}

The influence of benzenesulfonyl hydrazide concentration on the sensitivity of proposed method was studied for the range $2.5 \times 10^{-5}-10^{-4} \mathrm{M}$. The obtained results (Fig. 7) show that with increasing the benzenesulfonyl hydrazide concentration up to about $7.5 \times 10^{-5} \mathrm{M}$, the cathodic stripping peak currents of $\mathrm{Cu}-\mathrm{BSH}$ increased and then that was levelling off at higher concentrations. This is probably due to the competition of benzenesulfonyl hydrazide with copper complex for adsorption on the HMDE. So, an optimum benzenesulfonyl hydrazide concentration of $7.5 \times 10^{-5} \mathrm{M}$ was selected for subsequent investigations.

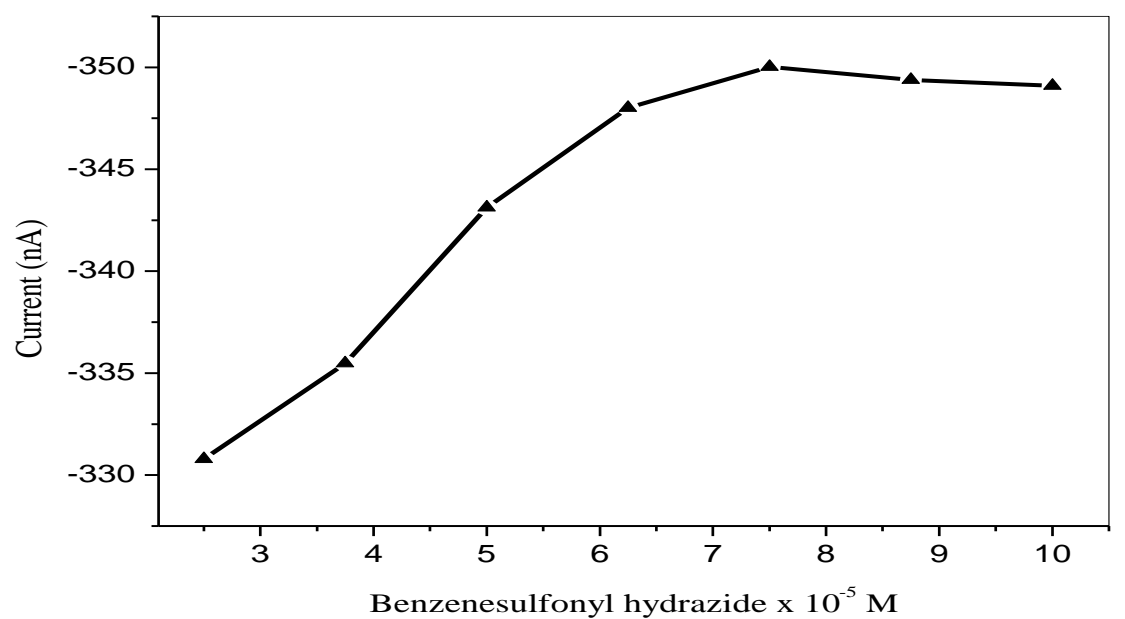

Figure 7. Effect of ligand concentration. Accumulation for $50 \mathrm{~s}$ at $-350 \mathrm{mV}$ in $0.03 \mathrm{M}$ perchloric acid containing $75 \mathrm{ng} \mathrm{mL}^{-1} \mathrm{Cu}$ (II). 


\section{Effect of wave pulse amplitude}

The impact of varying the excitation wave pulse amplitude on the current intensity was also evaluated. It was observed that the current was increased by increasing of pulse amplitude and the best shop of peak was observed at $50 \mathrm{mV}$ pulse amplitude. Thus, $50 \mathrm{mV}$ pulse amplitude was the ideal choice for this operational parameter.

\section{Interference studies}

Possible interference by other metals in the adsorptive stripping voltammetric determination of copper was investigated by the addition of the interfering ion to a solution containing $75 \mathrm{ng} \mathrm{mL}^{-1}$ of copper using the optimized conditions. The results of this study are proved that most of the foreign ions such as $\mathrm{K}^{+}, \mathrm{Na}^{+}, \mathrm{Ba}^{2+}, \mathrm{Mg}^{2+}, \mathrm{Co}^{2+}, \mathrm{Ni}^{2+}, \mathrm{Mn}^{2+}, \mathrm{Cr}^{3+}, \mathrm{Al}^{3+}$, $\mathrm{Ca}^{2+}, \mathrm{Zn}^{2+}, \mathrm{Pb}^{2+}$,and $\mathrm{Cd}^{2+}$ did not interfere for determination of copper.

\section{Calibration data}

Table 1 illustrates the percentage recovery, standard deviation, accuracy and precision. It is observed that the precision for two levels is 3.19 and $5.48 \%$. This is strong evidence that this method is precise and reproducible. Furthermore, the percentage recovery of the copper determination was tested by measurement of a standard reference material, and by comparison of results obtained by AdSV with those obtained by inductively coupled plasma sector field mass spectrometer (ICP-SFMS) for the same set of samples, two levels seronorm were used as the standard whole blood certified reference materials with the recommended concentration of copper are ranging between 97.37 to $103.11 \%$ which is an indication that this method is accurate for copper. The accuracy is ranging between 96.92 to $104.18 \%$. The results agreed within $5.5 \%$ with certified values.

The linear range for copper was evaluated at $50 \mathrm{~s}$ deposition time. The peak current increased linearly with copper concentration over the range $0.62-275 \mathrm{ng} \mathrm{mL}$, with correlation coefficient of 0.9999 . The detection limit of the investigated metal, defined as the metal concentration yielding an analytical peak equal to the minimum detectable one, can be calculated as the concentration that gives signal to background noise (blank) ratio equal to $3^{33}$. Note that the noise is a random fluctuations in the signal usually quantified using the standard deviation $\sigma$ of multiple measurements (10 measurements in this work) of a blank. Thus, the detection limit of the method with $3 \sigma$ criteria is $0.186 \mathrm{ng} \mathrm{mL}^{-1}$.

Table 1. Accuracy, precision and recovery of the method against a standard reference material

\begin{tabular}{ccccccc}
\hline Material & \multicolumn{2}{c}{ Mean $\pm \mathrm{SD}\left(\mu \mathrm{g} \mathrm{L}^{-1}\right)$} & Acceptable & Accuracy & Precision \\
& Certified & Measured & range $^{1}\left(\mu \mathrm{g} \mathrm{L}^{-1}\right)$ & $\%$ & $\begin{array}{c}\text { Recovery } \\
\%\end{array}$ & $\%$ \\
\hline (level 1,MR4206) & $564 \pm 5.4$ & $581.37 \pm 5.56$ & $531-597$ & 96.92 & 3.19 & 97.37 \\
\hline (level 3,O512627) & $1740 \pm 151$ & $1812 \pm 157.31$ & $1438-2042$ & 104.18 & 5.48 & 103.11 \\
\hline
\end{tabular}

${ }^{1}$ Seronorm ${ }^{\mathrm{TM}}$ Trace Elements Whole Blood, SERO AS, Billingstad, Norway

\section{Application to blood samples}

The developed method has been applied to blood samples for copper determination.

Because the amount of copper found in blood samples was quite high, so the dilution of the blood samples was performed accordingly. Reagent blanks were taken along with each set of the sample; the metal concentrations observed in these blank samples were negligible. 
The mean and standard deviation of the individual copper levels in the studied population was $912.92 \pm 240.33 \mu \mathrm{g} \mathrm{L}^{-1}$. The range for all samples was $451.89-1382.48 \mu \mathrm{g} \mathrm{L}^{-1}$. Table 2 summarizes the measured copper concentrations of thirty three healthy human in the western Algerian population. No significant differences were observed $\mathrm{P}<0.001$ in blood copper concentrations after applying to them the Student's t-test.

Table 2. Results of means copper concentrations, S.D.s, range, and 95\% confidence intervals for the mean present at blood samples of thirty three healthy human.

\begin{tabular}{cccc}
\hline $\mathrm{n}$ & Mean $\pm \mathrm{SD}\left(\mu \mathrm{g} \mathrm{L}^{-1}\right)$ & $95 \%$ Confidence & Range $\left(\mu \mathrm{g} \mathrm{L}^{-1}\right)$ \\
\hline 31 & $912.92 \pm 240.33$ & $823.32-1001.60$ & $451.89-1382.48$ \\
\hline
\end{tabular}

The level concentration of copper in this study (mean $912.92 \pm 240.33 \mu \mathrm{g} \mathrm{L}^{-1}$ ) is very much in line with the values for a Brazilian adolescent population $\left(920 \pm 176 \mu \mathrm{g} \mathrm{L}^{-1}\right)^{34}$, Swedish population $\left(950 \pm 100 \mu \mathrm{g} \mathrm{L}^{-1}\right)^{35}$, Germany population $\left(1020 \mu \mathrm{g} \mathrm{L}^{-1}\right)$ [36], population Spanish $\left(1070 \mu \mathrm{g} \mathrm{L}^{-1}\right)^{37}$ and for an adult population Italy $\left(1036 \mu \mathrm{g} \mathrm{L}^{-1}\right)^{38}$.

\section{Conclusion}

The present study demonstrates that stripping voltammetry of copper based on accumulation of copper - BSH complex can be used to determine trace amounts of copper in real samples. The detection limit of this technique is $0.186 \mathrm{ng} \mathrm{mL}^{-1}$ copper (II) at a collection period of $50 \mathrm{~s}$. This method offers a practical potential for trace determination of copper with high selectivity, sensitivity, simplicity and speed that have not been present together in the previously reported systems. In conclusion, this technique can be used for the on-site monitoring of biological samples.

\section{References}

1- S. La Fontaine, J.M. Quinn, S.S. Nakamoto, M.D. Page, V. Gohre, JL. Moseley, Eukaryotic Cell, 2002, 1, 736-757.

2- T.V. O’Halloran and V.C. Culotta, J. Biol. Chem, 2000, 275, 25057-25060.

3- P.L. Fox, Biometals, 2003, 16, 9-40.

4- T. Kaido, H. Hashimoto, H. Okamura, K. Tsukaguchi, J Clin Neurosci, 2005, 12, 205-208.

5- J. Bhattacharya, U.Choudhuri, O.Siwach, P.Sen, A.K. Dasgupta, Nanomedicine NBM, 2006, 2, 191-205.

6- M.A. Broderius, J.R Prohaska, Nutrition. Research, 2009, 29, 494-502.

7- C.G. Fraga, Molecular Aspects of Medicine, 2005, 26, 235-244.

8- B.R. Stern, M. Solioz, D. Krewski, P. Aggett, A. Tar-Ching, S. Baker, K. Crump, M. Dourson, L. Haber, R. Hertzberg, C. Keen, B. Meek, L. Rudenko, R. Schoeny, W. Slob, T. Starr, J. Toxicol .Environ. Health, 2007, 10, 157-222.

9- L. Gambling, H.S. Andersen, H.J. Mcardle, Biochemical Society, 2008, 36, 1258-1261.

10- B.E. Kim, M.L. Turski, Y. Nose, M. Casad, HA. Rockman, D.J. Thiele, Cell Metabolism, 2010, 11, 353-363.

11- G. Hanrahan, G. Deepa. P. Wang, J Environ Monit, 2004, 6, 657-664. 
12- L. Yonghong, L. Xiaoying, Z. Xiandong, L. Yong, L. Xiaotao, W. Wanzhi, L. Shenglian, Sens Actuators B, 2009, 139, 604-610.

13- W. Shujie, Y. Baoxian, Electroanalysis, 2008, 20, 984-988.

14- H. Mojtaba, R. Ahmad, Y. Mohammad, Sens Actuators B, 2011, 160, 121-130.

15- X. Xianrong, L. Su, Y. Jinghua, L. Wenjing, H. Jiadong, Biosens Bioelectron, 2012, 31, 277-283.

16- G. Waldemar, AC. James, Anal Chem, 2012, 64, 2706-2710.

17- AF. Al-Ghamdi, Am J Anal Chem, 2011, 2, 174-181.

18- E.O. Averyaskina, S.S. Ermakov,_L.N. Moskvin, J Anal Chem, 2006, 61,1100-1103.

19- MR. Town, P. Herman, V. Leeuwen, Electroanal Chem, 2002, 535, 11-25.

20- R. Štěpánl, J. Barekl, V. Mejstř́ík, J. Zimal, Sensors 2003, 3, 43-60.

21- B. Yosypchuk, M. Fojta, L. Havran, M. Heyrovsky, E. Palecek, Electroanalysis, 2006, 18, 186-194.

22- G. Chin, J. Chong, A. Kluczewska, A. Lau, S. Gorjy, M. Tennant, Australian Dental Journal, 2000, 45, 246-249.

23- D.S. Djenaine, H.M. Lucia, F.F. Orlando, Int J Anal Chem 2011, 2011, 1-8.

24- A. Doménech-Carbó, M.T. Doménech-Carbó, M. Moya-Moreno, J.V. GimenoAdelantado, F. Bosch-Reig, Analytica Chimica Acta, 2000,407, 275-289.

25- M. Hepel, Electroanalysis, 1990, 2, 319-326.

26- E. Czop, A. Economou, A. Bobrowski, Electrochimica Acta, 2011, 56, 2186-2202.

27- A.G. Fogg, J. Wang, Pure Appl Chem, 1999, 71, 891-897.

28- A. Safavi, E. Shams, Anal Chim Acta, 1999, 385, 265-272.

29- M. Pesavento, G. Alberti, R. biesuz, Anal Chim Acta, 2009, 631, 129-141.

30- T. Khayamian, A.A. Ensafi, A. Benvidi, Talanta, 2006, 69, 1176-1181.

31. A.A. Ensafi , T. Khayamian, A. Benvidi, E. Mirmomtaz, Anal Chim Acta, 2006, 561, 225-232.

32. R.K. Mahajan, $\uparrow$ T. P. S. Walia, Sumanjit, T. S. Lobana, Analytical Sciences. 2006, 22 , 389-392.

33. B.C. Househam, C.M.G. Van den Berg, J.P. Riley, 1987 Anal. Chim. Acta, 1987, 200, 291-303.

34. J.L. Rodrigues, B. L. Batista, M. Fillion, C.J.S. Passos, D. Mergler, F.J. Barbosa, Sci Total Environ, 2009, 407, 4168-4173.

35. E. Bárány, I. A. Bergdahl, L. E. Bratteby, T. Lundh, A. G. Samuelson, B. A. Schutz, Sci. Total Environ, 2002, 286, 129-141.

36. P. Heitland, H. D. Koster, J Trace Elem Med Biol, 2006, 20, 253-262.

37. M.A. Moreno, C. Marin, F. Vinagre, P, Ostapczuk, Sci Total. Environ, 1999, 229, 209215.

38. B. Bocca, R. Madeddu, Y. Asara, P. Tolu, J.A. Marchal, G. Forte, J Trace Elem Med Biol, 2011, 25, 19-26. 